\title{
Coronary Circulatory Function in Patients with the Metabolic Syndrome
}

\author{
Marcelo F. Di Carli ${ }^{1,2}$, David Charytan ${ }^{3}$, Graham T. McMahon ${ }^{4}$, Peter Ganz ${ }^{2}$, Sharmila Dorbala ${ }^{1}$, and \\ Heinrich R. Schelbert ${ }^{5}$ \\ ${ }^{I}$ Noninvasive Cardiovascular Imaging Program, Departments of Medicine (Cardiology) and Radiology, and Division of Nuclear \\ Medicine and Molecular Imaging, Department of Radiology, Brigham and Women's Hospital, Harvard Medical School, Boston \\ Massachusetts; ${ }^{2}$ Division of Cardiology, Department of Medicine, Brigham and Women's Hospital, Harvard Medical School, Boston \\ Massachusetts; ${ }^{3}$ Division of Nephrology, Department of Medicine, Brigham and Women's Hospital, Harvard Medical School, Boston \\ Massachusetts; ${ }^{4}$ Division of Endocrinology, Department of Medicine, Brigham and Women's Hospital, Harvard Medical School, \\ Boston Massachusetts; and ${ }^{5}$ UCLA School of Medicine, Los Angeles, California
}

The metabolic syndrome affects $25 \%$ of the U.S. population and greatly increases the risk of diabetes and coronary artery disease (CAD). We tested the hypothesis that the metabolic syndrome is associated with impaired coronary vasodilator function, a marker of atherosclerotic disease activity. Methods: Four hundred sixty-two patients at risk for CAD, as defined by a low-density lipoprotein cholesterol $\geq 160 \mathrm{mg} / \mathrm{dL}$ with fewer than 2 coronary risk factors, a low-density lipoprotein cholesterol $\geq 130 \mathrm{mg} / \mathrm{dL}$ with 2 or more coronary risk factors, or with documented CAD were included. A subset of 234 individuals underwent repeated PET at $1 \mathrm{y}$. Myocardial blood flow (MBF) and vasodilator reserve were assessed by PET. Modified criteria of the National Cholesterol Education Program, Adult Treatment Panel III were used to characterize the metabolic syndrome. Results: Adenosine- and cold-stimulated MBF were similar in patients with and without metabolic syndrome, whereas baseline MBF showed a stepwise increase with increasing features of the syndrome. Consequently, patients with metabolic syndrome showed a lower coronary flow reserve (CFR) $(2.5 \pm 1.0)$ than those without metabolic syndrome $(3.0 \pm$ $0.9, P=0.004)$. Differences in CFR were no longer present after correcting rest flows for the rate-pressure product. Change in MBF and CFR at $1 \mathrm{y}$ were not different across groups of patients with increasing features of the metabolic syndrome. Conclusion: Patients with metabolic syndrome demonstrate impaired CFR, which is related to the augmentation in resting coronary blood flow caused by hypertension. In high-risk individuals, peak adenosine- and cold-stimulated blood flows are impaired even in the absence of the metabolic syndrome.

Key Words: cardiology (clinical); PET/CT; other; coronary blood flow; metabolic syndrome

J Nucl Med 2011; 52:1369-1377

DOI: 10.2967/jnumed.110.082883

Received Aug. 31, 2010; revision accepted Jun. 22, 2011.

For correspondence or reprints contact: Marcelo F. Di Carli, Brigham and

Women's Hospital, ASB-L1 037-C, Boston, MA.

E-mail: mdicarli@partners.org

Guest Editor: Gerold Porenta, Rudolfinerhaus

Published online Aug. 17, 2011.

COPYRIGHT $\odot 2011$ by the Society of Nuclear Medicine, Inc. n 1988, Reaven demonstrated that a cluster of risk factors, including abdominal obesity, hypertension, impaired fasting glucose, and dyslipidemia, was strongly associated with the risk of coronary artery disease (CAD) (1). The term metabolic syndrome emerged to describe this clustering, and metabolic syndrome is now recognized to have a prevalence of $25 \%$ of the adult population of the United States (2).

Vascular dysfunction, including that caused by endothelial dysfunction, is an early abnormality in the metabolic syndrome that may contribute to premature atherosclerosis (3). Each of the components of the metabolic syndrome has been independently associated with vascular dysfunction (4-8). In addition to insulin resistance, release of proinflammatory cytokines (e.g., interleukin-6, tumor necrosis factor$\alpha$ ) by visceral adipose tissue or other as yet undefined factors may also contribute to vascular dysfunction (9) or adverse clinical outcomes $(10,11)$ in patients with the metabolic syndrome. However, they do not together fully explain the 2.6-fold increased risk of coronary death among those with the metabolic syndrome (12), suggesting that other mechanisms may contribute to the association between the metabolic syndrome and the increased risk of CAD. One such mechanism may involve the potential adverse effect of features of the metabolic syndrome on vascular function and, in particular, endothelial function, thereby increasing the potential for atherothromobotic complications (13).

We tested the hypothesis that the metabolic syndrome is associated with impaired coronary vascular function in a large cohort of high-risk patients with diverse risk factors, including the metabolic syndrome and established CAD.

\section{MATERIALS AND METHODS}

\section{Patient Population}

We included men and women (18-75 y) at risk for or with documented CAD, who completed the screening phase of the RAMPART (Relative and Absolute Myocardial Perfusion changes as measured by Positron Emission Tomography to Assess the Effects of ACAT Inhibition: A Double-Blind, Randomized, Con- 
trolled, Multicenter Trial). The RAMPART was a phase II clinical trial designed to determine the effects of avasimibe (Acyl coenzyme A: cholesterol acyltransferase inhibitor) on myocardial blood flow $(\mathrm{MBF})$ in patients with documented or at risk for CAD. Patients were considered to have CAD if they had a history of stable angina, a positive stress electrocardiogram, an abnormal stress myocardial perfusion or stress echocardiography study, an abnormal coronary angiogram, or prior revascularization. Patients with a low-density lipoprotein cholesterol (LDL-C) $\geq 160 \mathrm{mg} / \mathrm{dL}$ with fewer than 2 coronary risk factors or an LDL-C $\geq 130 \mathrm{mg} / \mathrm{dL}$ with 2 or more coronary risk factors were considered to be at risk for CAD. Women of childbearing potential were excluded, as were patients with known diabetes, advanced renal dysfunction, active liver disease or hepatic dysfunction, skeletal myopathy, uncontrolled hypertension, valvular heart disease, symptomatic heart failure, historical or diagnostic evidence of left ventricular hypertrophy, unstable angina pectoris, or dilated cardiomyopathy (left ventricular ejection fraction $<40 \%$ ).

Individuals with a coronary flow reserve less than 2.5 in at least 1 arterial territory or a stress defect occupying $\geq 15 \%$ of at least 1 coronary territory received a low-cholesterol diet for $4 \mathrm{wk}$. Individuals with a low-density lipoprotein (LDL) $\geq 100 \mathrm{mg} / \mathrm{dL}$ after $4 \mathrm{wk}$ on this diet were randomized to $1 \mathrm{y}$ of therapy with avasimibe plus atorvastatin $(10 \mathrm{mg} / \mathrm{d})$ or atorvastatin plus placebo. Two hundred thirty-four patients who met these criteria were randomized and underwent repeated scanning at $1 \mathrm{y}$.

\section{Definition of Metabolic Syndrome}

A battery of risk factors and other demographic variables were assessed at baseline, allowing classification of the patients in the study according to the number of components of the metabolic syndrome, on the basis of the modified criteria of the National Cholesterol Education Program (NCEP) (14), with body mass index (BMI) in place of waist circumference $(10,15,16)$. Accordingly, the 5 thresholds used were triglycerides level $\geq 150 \mathrm{mg} / \mathrm{dL}$, high-density lipoprotein cholesterol (HDL-C) $<40 \mathrm{mg} / \mathrm{dL}$ in men and $<50 \mathrm{mg} / \mathrm{dL}$ in women, systolic blood pressure $\geq 130 \mathrm{~mm} \mathrm{Hg}$ or diastolic blood pressure $\geq 85 \mathrm{~mm}$ $\mathrm{Hg}$, fasting glucose $\geq 110 \mathrm{mg} / \mathrm{dL}$, and BMI $>28.8 \mathrm{~kg} / \mathrm{m}^{2}$ (16). According to the NCEP, patients were considered as having metabolic syndrome if they fulfilled 3 or more of these criteria.

\section{Measurements of MBF}

Patients underwent PET for assessment of MBF using wholebody PET tomographs (Siemens/CTI) at 12 U.S. sites. All subjects refrained from caffeine-containing beverages or theophyllinecontaining medications for $24 \mathrm{~h}$ before the PET study. Patients using calcium channel blockers or $\beta$-blockers were instructed to withhold the medications for $24 \mathrm{~h}$ before the PET study. All subjects were studied in the fasting state.

MBF was measured at rest and during peak hyperemia as described previously (17) using ${ }^{13} \mathrm{~N}$-ammonia. A 10 - to 15 -min transmission scan was acquired for correction of photon attenuation. Beginning with the intravenous bolus administration of ${ }^{13} \mathrm{~N}$-ammonia $(10.582 \mathrm{MBq} / \mathrm{kg}[0.286 \mathrm{mCi} / \mathrm{kg}])$, serial images were acquired for $19 \mathrm{~min}$. Thirty minutes later, adenosine $(0.14 \mathrm{mg} / \mathrm{kg} / \mathrm{min})$ was infused intravenously for $6 \mathrm{~min}$. Three minutes into the adenosine infusion, a second dose of ${ }^{13} \mathrm{~N}$-ammonia was injected, and images were recorded in the same acquisition sequence. In a subgroup of patients $(n=109)$, cold pressor testing was also performed as previously described (17). Briefly, cold stimulation was performed by immersing the patient's hand and forearm in ice water (equal parts of ice and water at $0^{\circ} \mathrm{C}-2{ }^{\circ} \mathrm{C}$ ) for $3 \mathrm{~min}$. Ninety seconds into the cold stimulus, a third dose of ${ }^{13} \mathrm{~N}$-ammonia $(10.582 \mathrm{MBq} / \mathrm{kg}[0.286 \mathrm{mCi} / \mathrm{kg}])$ was injected, and images were recorded in the same manner. The heart rate, blood pressure, and 12-lead electrocardiogram were recorded at baseline and throughout the infusion of adenosine and the cold pressor test. Imaging equipment used in the trial was validated for quality control and measurement of reproducibility by a core laboratory (UCLA School of Medicine). Image acquisition protocols were standardized at each site, and MBF was measured at the core laboratory.

\section{Data Analysis}

The serially acquired transaxial images were reoriented into short-axis slices of the heart and assembled into serial polar maps. Regions of interest were assigned to coronary vascular territories on the last 15-min polar map and copied to the serial polar maps acquired during the initial $2 \mathrm{~min}$ after intravenous ${ }^{13} \mathrm{~N}$-ammonia injection. An additional small, circular region of interest was assigned to the center of the left ventricular blood pool. Regional myocardial and blood-pool time-activity curves were then generated. In each coronary territory, MBF was calculated by fitting the ${ }^{13} \mathrm{~N}$-ammonia time-activity curves with a 2-compartment tracer kinetic model. The coronary flow reserve (primary study endpoint) was defined as the ratio between hyperemic and basal MBF. An index of coronary vascular resistance was calculated by dividing the mean arterial blood pressure by MBF. Coronary flow reserve and resistance values are the average of the entire left ventricular myocardium, except for patients with perfusion defects, for whom the values derived from the regional perfusion defect are reported. To account for differences in cardiac work, resting MBF values were normalized to the corresponding rate-pressure product by dividing the resting blood flow value by the rate-pressure product (an index of cardiac work), multiplied by a linear factor of 10,000 in each individual patient. Corrected coronary flow reserve was also calculated as the ratio between hyperemic and normalized basal MBF.

\section{Laboratory Analyses}

A central laboratory (Medical Research Laboratories) performed all clinical and lipid analyses as specified by the standardization program of the Centers for Disease Control and Prevention and the National Heart, Lung and Blood Institute (18). Venous plasma and serum samples were taken after an overnight fast. Plasma glucose was measured by the glucose oxidase method. Plasma total cholesterol and total triglycerides were determined enzymatically with the Hitachi 747 analyzer (19). Plasma HDL-C was determined enzymatically after LDL-C and very-low-density lipoprotein cholesterol were selectively removed from the plasma sample by heparin and magnesium chloride precipitation (20). LDL-C was calculated using the Friedewald formula (21), except in situations in which triglycerides were greater than $400 \mathrm{mg} / \mathrm{dL}$, at which time LDL-C was derived using the $\beta$-Quant method. C-reactive protein (CRP) was measured using a latex-enhanced immunonephelometric assay on a BN II analyzer (Dade Behring) (22). Plasminogen activator inhibitor type 1 (PAI1) levels were measured using a commercially available sandwich enzyme-linked immunosorbent assay (R\&D Systems and American Diagnostics). Serum creatinine and BUN were also obtained.

\section{Statistical Analysis}

Data are presented as mean \pm SD. Differences in baseline characteristics of patients, coronary blood flow, coronary vascular resistance, and coronary flow reserve between groups were compared using single-factor ANOVA. Significant main effects for 
group were followed with Tukey post hoc tests to identify differences between groups. A MANCOVA design was used to investigate differences in adjusted MBF, coronary vascular resistance, and flow reserve between groups. Independent predictors of changes in coronary flow reserve in response to adenosine at baseline and the change in vasodilator reserve over time were investigated using multiple-regression analysis. The SPSS statistical package (version 18; SPSS Software) was used for analyses. For all analyses, an $\alpha$ of 0.05 was used to define statistical significance.

\section{RESULTS}

\section{Baseline Characteristics}

Table 1 summarizes the baseline characteristics of the study population. Sex distribution and the proportion of active smokers and patients with $\mathrm{CAD}$ were similar in the 3 groups studied. As expected, there was a stepwise increase in BMI, total cholesterol, triglycerides, triglyceride/HDL-C ratio (a close correlate of insulin resistance/hyperinsulinemia) $(23,24)$, plasma glucose, and blood pressure, with the characteristic stepwise reduction in HDL-C with increasing number of features of the metabolic syndrome. There was no difference in LDL-C between the groups.

\section{Differences in CRP and PAI-1 Levels}

CRP and PAI-1 levels were available for 293 patients. Figure 1 demonstrates stepwise increases in both CRP and PAI-1 levels with increasing features of the metabolic syndrome, confirming the correct characterization of patients in the study (25).

\section{MBF, Coronary Vascular Resistance, and Flow \\ Reserve in Patients with Metabolic Syndrome}

Table 2 summarizes the differences in MBF and coronary vascular resistance in the study groups. There was a stepwise increase in baseline MBF with increasing features of the metabolic syndrome, reflecting the increase in blood pressure and, consequently, cardiac work and myocardial oxygen demand in patients with metabolic syndrome. In fact, these differences were no longer present after normalization of resting blood flow by the rate-pressure product, as an index of cardiac work.

During peak hyperemia, MBF increased and coronary vascular resistance decreased significantly in the 3 groups. However, peak adenosine-stimulated MBF was similar in the 3 groups (Fig. 2). Similar results were observed when only patients without CAD were analyzed (Table 3 ).

Consequently, there was a reduction in coronary flow reserve with increasing features of the metabolic syndrome (Fig. 3). Patients with 3 or more features of the syndrome showed a $17 \%$ relative reduction in coronary flow reserve compared with those without metabolic syndrome (Fig. 3, top), even after adjusting for age, sex, and a history of prior CAD. However, the difference in flow reserve was no longer seen after correcting the rest flows for the rate-pressure product (Fig. 3, bottom).

In the subgroup of patients who underwent cold pressor testing ( $n=109)$, MBF increased significantly in the 3 groups studied (Table 2). However, the magnitude of flow increase was similar in the 3 groups (Fig. 4). Comparable results were observed when only patients without CAD were analyzed (Table 3).

\section{Predictors of Abnormalities in Coronary Flow Reserve in Patients with Metabolic Syndrome}

Multivariable modeling including age, sex, a history of prior $\mathrm{CAD}$, a history of active smoking, and the modified NCEP diagnostic criteria for metabolic syndrome (fasting

TABLE 1

Baseline Characteristics of Patients

\begin{tabular}{|c|c|c|c|c|c|}
\hline \multirow[b]{2}{*}{ Variable } & \multirow[b]{2}{*}{ All patients } & \multicolumn{3}{|c|}{ Patients with features of metabolic syndrome } & \multirow[b]{2}{*}{$P$} \\
\hline & & No features & 1 or 2 features & 3 or more features & \\
\hline Age $(y)$ & $58 \pm 10$ & $56 \pm 11$ & $59 \pm 10$ & $56 \pm 10$ & 0.01 \\
\hline Female sex & $129(28)$ & $9(24)$ & $74(30)$ & $46(25)$ & 0.46 \\
\hline Smokers & 87 (19) & $9(24)$ & $36(15)$ & $42(23)$ & 0.06 \\
\hline Prior CAD & $115(25)$ & $4(11)$ & $60(25)$ & $51(28)$ & 0.07 \\
\hline $\mathrm{BMI}$ & $30 \pm 6$ & $25 \pm 2$ & $28 \pm 4$ & $33 \pm 7$ & $<0.001$ \\
\hline Total cholesterol (mg/dL) & $241 \pm 46$ & $228 \pm 36$ & $240 \pm 46$ & $245 \pm 48$ & 0.09 \\
\hline $\mathrm{HDL}-\mathrm{C}(\mathrm{mg} / \mathrm{dL})$ & $46 \pm 13$ & $52 \pm 9$ & $51 \pm 13$ & $39 \pm 9$ & $<0.001$ \\
\hline LDL-C (mg/dL) & $152 \pm 41$ & $152 \pm 33$ & $153 \pm 38$ & $152 \pm 46$ & 0.97 \\
\hline Triglycerides (mg/dL) & $220 \pm 162$ & $114 \pm 23$ & $186 \pm 132$ & $288 \pm 187$ & $<0.001$ \\
\hline Triglyceride/HDL-C & $5.6 \pm 6.3$ & $2.3 \pm 0.7$ & $4.2 \pm 4.7$ & $8.3 \pm 7.7$ & $<0.001$ \\
\hline Plasma glucose (mg/dL) & $98 \pm 19$ & $88 \pm 10$ & $94 \pm 11$ & $105 \pm 25$ & $<0.001$ \\
\hline Blood urea nitrogen (mg/dL) & $16 \pm 4$ & $16 \pm 3$ & $16 \pm 4$ & $16 \pm 4$ & 0.69 \\
\hline Creatinine (mg/dL) & $1.15 \pm 0.17$ & $1.15 \pm 0.14$ & $1.13 \pm 0.18$ & $1.18 \pm 0.17$ & 0.02 \\
\hline Rest heart rate (bpm) & $62 \pm 11$ & $59 \pm 9$ & $61 \pm 10$ & $63 \pm 11$ & 0.09 \\
\hline Systolic blood pressure $(\mathrm{mm} \mathrm{Hg})$ & $132 \pm 21$ & $112 \pm 10$ & $132 \pm 21$ & $135 \pm 19$ & $<0.001$ \\
\hline Diastolic blood pressure (mm Hg) & $71 \pm 10$ & $65 \pm 9$ & $72 \pm 10$ & $73 \pm 10$ & $<0.001$ \\
\hline Rest rate-pressure product & $8,158 \pm 2,072$ & $6,623 \pm 1,089$ & $8,111 \pm 2,048$ & $8,146 \pm 2,112$ & $<0.001$ \\
\hline $\begin{array}{l}\text { bpm }=\text { beats per minute. } \\
n=462 \text { for all patients; } 37 \text { for pat } \\
\text { tients with } 3 \text { or more features. Data }\end{array}$ & $\begin{array}{l}\text { with no featur } \\
\text { mean } \pm S D \text {, or }\end{array}$ & metabolic sy & $\begin{array}{l}\text { ne, } 244 \text { for pat } \\
\text { arentheses. }\end{array}$ & with 1 or 2 feature & d 181 for \\
\hline
\end{tabular}


FIGURE 1. Relationship between mean CRP and PAl-1 levels and features of metabolic syndrome. ${ }^{*} P=0.03$ vs. none, and $P=0.001$ vs. 1 or $2 .{ }^{\dagger} P=0.05$ vs. none, and $P<0.001$ vs. 1 or 2 .

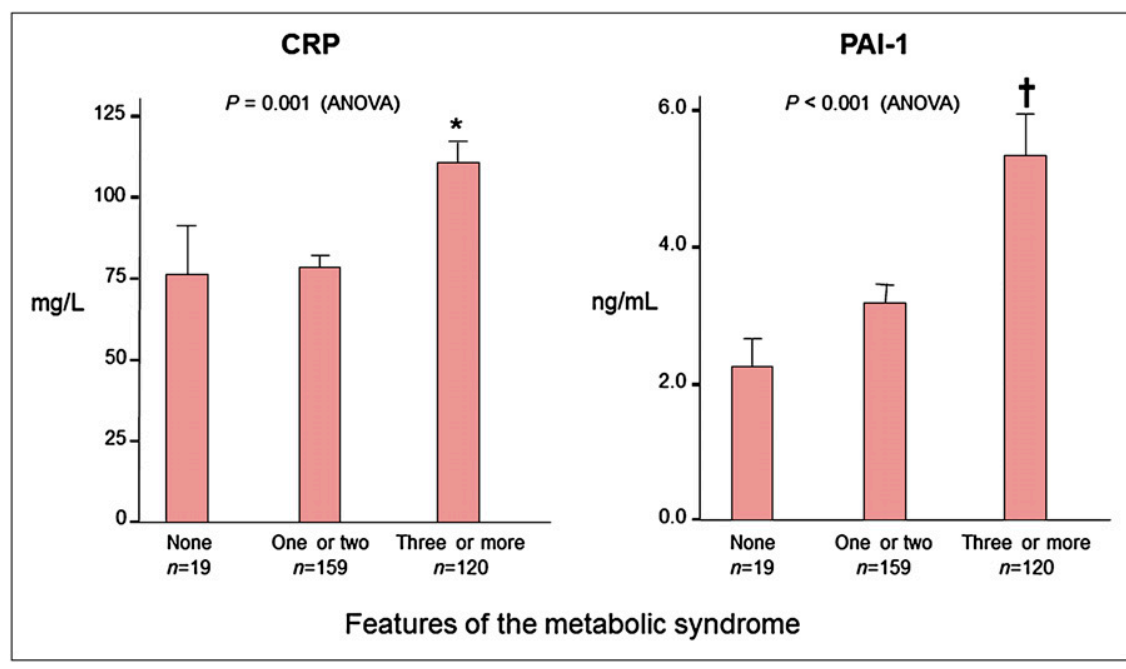

glucose, triglycerides, blood pressure, HDL-C, and BMI) was performed to identify factors associated with coronary flow reserve. In the final model $(R=0.35, P<0.001)$, variables associated with an impaired coronary flow reserve were hypertension $\left(R^{2}\right.$ change $\left.=0.04, \mathrm{~F}_{460}=20, P<0.001\right)$, male sex $\left(R^{2}\right.$ change $=0.03, \mathrm{~F}_{459}$ change $\left.=13, P<0.001\right)$, a history of prior $\mathrm{CAD}\left(R^{2}\right.$ change $\left.=0.03, \mathrm{~F}_{458}=15, P<0.001\right)$, age $\left(R^{2}\right.$ change $=0.01, \mathrm{~F}_{457}$ change $\left.=7, P=0.01\right)$, and active smoking $\left(R^{2}\right.$ change $\left.=0.008, \mathrm{~F}_{456}=4, P=0.04\right)$. A similar model in patients without CAD revealed $(R=0.37, P<$ $0.001)$ that impaired coronary flow reserve was associated with male sex $\left(R^{2}\right.$ change $\left.=0.07, \mathrm{~F}_{340}=24, P<0.001\right)$, age $\left(R^{2}\right.$ change $=0.04, \mathrm{~F}_{339}$ change $\left.=16, P<0.001\right)$, a history of hypertension $\left(R^{2}\right.$ change $\left.=0.02, \mathrm{~F}_{338}=6, P=0.012\right)$, and active smoking $\left(R^{2}\right.$ change $\left.=0.01, \mathrm{~F}_{337}=4, P=0.04\right)$.

To determine the relative contribution of systemic inflammation and PAI-1 levels to the impaired coronary flow reserve, a separate multivariable analysis was per- formed in the subgroup of patients with CRP and PAI-1 data. In addition to the variables included in the original model, CRP and PAI-1 were also considered in this analysis. In this model $(R=0.31, P<0.001)$, impaired coronary flow reserve was associated with active smoking $\left(R^{2}\right.$ change $=$ $0.03, \mathrm{~F}_{291}$ change $=10, P=0.002$ ), a history of prior CAD $\left(R^{2}\right.$ change $=0.02, \mathrm{~F}_{290}$ change $\left.=6, P=0.011\right)$, male sex $\left(R^{2}\right.$ change $=0.03, \mathrm{~F}_{289}$ change $\left.=8, P=0.006\right)$, and the PAI-1 level $\left(R^{2}\right.$ change $=0.02, \mathrm{~F}_{288}$ change $=6, P=$ 0.017). The CRP level was not a predictor of impaired coronary flow reserve $(P=0.95)$.

\section{Change in MBF and Coronary Vascular Resistance over Time}

MBF was measured in a subset of 234 patients after $1 \mathrm{y}$ of randomized therapy. Associations between the metabolic syndrome and the change in indices of MBF over time are summarized in Table 4. Within this subset, there were non-

TABLE 2

MBF and Coronary Vascular Resistance in All Study Patients

\begin{tabular}{|c|c|c|c|c|}
\hline \multirow[b]{2}{*}{ Variable } & \multirow[b]{2}{*}{ All patients } & \multicolumn{3}{|c|}{ Patients with features of metabolic syndrome } \\
\hline & & No features & 1 or 2 features & 3 or more features \\
\hline \multicolumn{5}{|l|}{$\mathrm{MBF}(\mathrm{mL} / \mathrm{min} / \mathrm{g})$} \\
\hline Baseline & $0.78 \pm 0.25$ & $0.65 \pm 0.15$ & $0.78 \pm 0.26$ & $0.80 \pm 0.25$ \\
\hline Baseline-corrected & $0.97 \pm 0.23$ & $0.99 \pm 0.21$ & $0.98 \pm 0.24$ & $0.94 \pm 0.22$ \\
\hline Adenosine & $1.88 \pm 0.68$ & $1.90 \pm 0.59$ & $1.83 \pm 0.64$ & $1.94 \pm 0.75$ \\
\hline Coronary vasodilator reserve & $2.6 \pm 1.0$ & $3.0 \pm 0.9$ & $2.5 \pm 0.9$ & $2.5 \pm 1.0$ \\
\hline Coronary vasodilator-reserve corrected & $1.96 \pm 0.7$ & $2.0 \pm 0.6$ & $1.9 \pm 0.7$ & $2.03 \pm 0.7$ \\
\hline \multicolumn{5}{|c|}{ Coronary vascular resistance $(\mathrm{mL} / \mathrm{min} / \mathrm{g} / \mathrm{mm} \mathrm{Hg})$} \\
\hline Baseline & $127 \pm 37$ & $131 \pm 33$ & $126 \pm 37$ & $127 \pm 38$ \\
\hline Adenosine & $54 \pm 23$ & $50 \pm 22$ & $54 \pm 21$ & $55 \pm 25$ \\
\hline Cold pressor test* $(\mathrm{mL} / \mathrm{min} / \mathrm{g})$ & $0.90 \pm 0.31$ & $0.72 \pm 0.25$ & $0.94 \pm 0.32$ & $0.87 \pm 0.29$ \\
\hline Increase from baseline* (\%) & $17 \pm 30$ & $13 \pm 12$ & $21 \pm 30$ & $12 \pm 30$ \\
\hline
\end{tabular}

${ }^{*}$ Cold pressor testing was performed on only a subgroup of patients ( $\left.n=109\right)$, of whom 7 had no features of metabolic syndrome, 54 had 1 or 2 features, and 48 had 3 or more features. Rest of table contains data for entire group of patients ( $n=462)$, of whom 37 had no features of metabolic syndrome, 244 had 1 or 2 features, and 181 had 3 or more features.

Data are mean $\pm \mathrm{SD}$. 


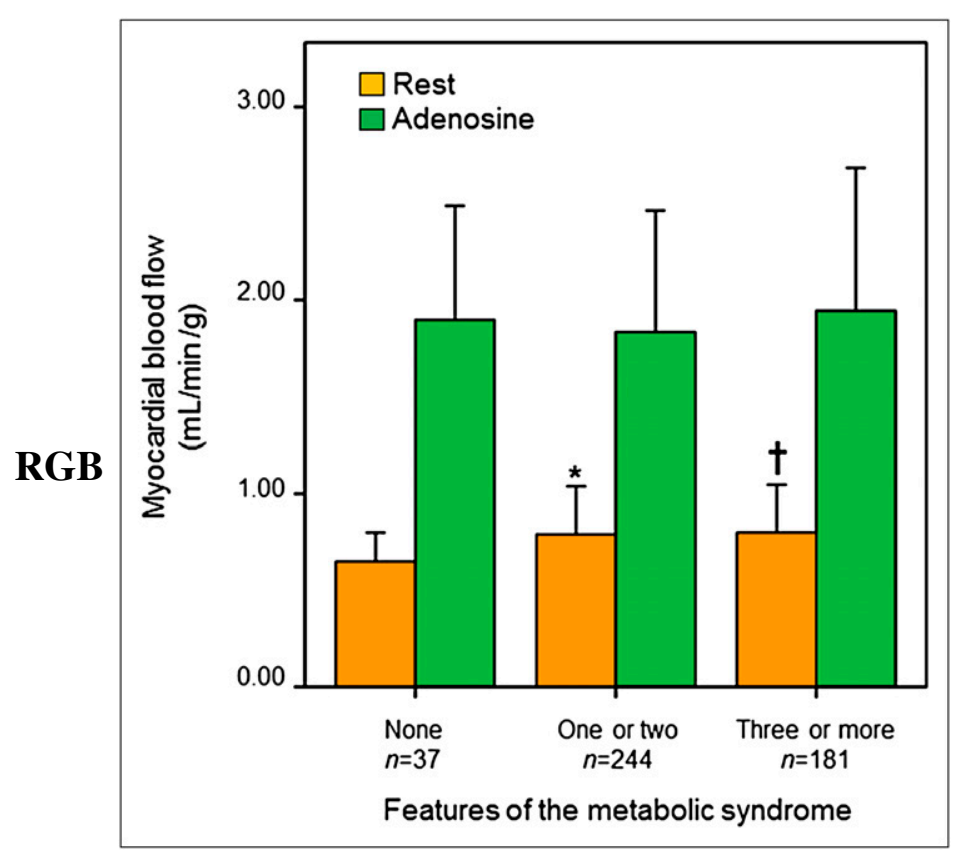

FIGURE 2. Relationship between mean rest and adenosine-stimulated coronary blood flow and features of metabolic syndrome. ${ }^{\star} P=$ 0.007 vs. none. ${ }^{\dagger} P=0.003$ vs. none.

significant trends toward a stepwise increase in resting MBF at baseline $(P=0.07)$ and a decrease in baseline coronary vascular resistance $(P=0.07)$ with increasing features of the metabolic syndrome. Conversely, there was a significant decrease in coronary vasodilator reserve with increasing features of the metabolic syndrome $(P=$ $0.01)$. In unadjusted analyses, there were no significant differences in the change in MBF or vascular resistance between individuals with $0,1-2$, or 3 or more parameters of the metabolic syndrome (Table 3 ). In multivariable anal- yses adjusted for randomized therapy, only age of 40-60 y $(R=-00.79, P=0.03)$ and more than $60 \mathrm{y}(R=-1.04$, $P=0.006)$, compared with age less than $40 \mathrm{y}$, were significant predictors of an increased loss in vasodilator reserve over time. The number of components of the metabolic syndrome was not associated with the change in vasodilator reserve at $1 \mathrm{y}$ in models incorporating indicator variables for the components of the syndrome.

\section{DISCUSSION}

This study demonstrates in a large cohort of patients that coronary flow reserve, as a measure of vascular health, is impaired in high-risk patients with the metabolic syndrome. Subjects with metabolic syndrome, based on the presence of 3 or more NCEP diagnostic criteria, showed a significant $17 \%$ relative reduction in coronary flow reserve, compared with subjects without the syndrome. This difference persisted after adjusting for age, sex, and a history of prior $\mathrm{CAD}$. This reduction in coronary flow reserve appeared to be related to an increase in resting MBF rather than reduced peak adenosine-stimulated blood flow. Indeed, coronary flow reserve was similar in all groups studied when corrected rest blood flow (for rate-pressure product) was used in the calculation of flow reserve. Likewise, in subgroup analysis all 3 groups showed similar increases in MBF in response to cold pressor testing. These results were consistent in patients with and without overt CAD.

Patients in the RAMPART study were recruited on the basis of the presence of either dyslipidemia (LDL $>130 \mathrm{mg} /$ $\mathrm{dL}$ ) or documented CAD and did not include healthy controls. However, all 3 groups in our study had a peak adenosine-stimulated MBF that was approximately $20 \%$ lower than that reported among age-matched healthy controls using the same methodology $(8,26)$. Similarly, the increase in

TABLE 3

MBF and Coronary Vascular Resistance in Only Patients Without CAD

\begin{tabular}{|c|c|c|c|c|c|}
\hline \multirow[b]{2}{*}{ Variable } & \multirow[b]{2}{*}{ All patients } & \multicolumn{3}{|c|}{ Patients with features of metabolic syndrome } & \multirow[b]{2}{*}{$P$} \\
\hline & & No features & 1 or 2 features & 3 or more features & \\
\hline \multicolumn{6}{|l|}{$\operatorname{MBF}(\mathrm{mL} / \mathrm{min} / \mathrm{g})$} \\
\hline Baseline & $0.78 \pm 0.25$ & $0.66 \pm 0.15$ & $0.80 \pm 0.26$ & $0.80 \pm 0.24$ & 0.008 \\
\hline Baseline-corrected & $0.97 \pm 0.23$ & $1.0 \pm 0.21$ & $0.98 \pm 0.24$ & $0.94 \pm 0.22$ & 0.221 \\
\hline Adenosine & $1.95 \pm 0.63$ & $1.85 \pm 0.55$ & $1.91 \pm 0.62$ & $2.03 \pm 0.66$ & 0.181 \\
\hline Coronary vasodilator reserve & $2.6 \pm 0.9$ & $2.9 \pm 0.9$ & $2.6 \pm 0.9$ & $2.7 \pm 1.0$ & 0.133 \\
\hline Coronary vasodilator reserve-corrected & $2.0 \pm 0.6$ & $1.9 \pm 0.5$ & $1.99 \pm 0.6$ & $2.13 \pm 0.7$ & 0.105 \\
\hline \multicolumn{6}{|l|}{$\begin{array}{l}\text { Coronary vascular resistance } \\
\qquad(\mathrm{mL} / \mathrm{min} / \mathrm{g} / \mathrm{mm} \mathrm{Hg})\end{array}$} \\
\hline Baseline & $127 \pm 38$ & $130 \pm 34$ & $125 \pm 39$ & $127 \pm 37$ & 0.747 \\
\hline Adenosine & $51 \pm 18$ & $51 \pm 22$ & $51 \pm 18$ & $50 \pm 17$ & 0.836 \\
\hline Cold pressor test $(\mathrm{mL} / \mathrm{min} / \mathrm{g})$ & $0.91 \pm 0.31$ & $0.74 \pm 0.27$ & $0.97 \pm 0.34$ & $0.87 \pm 0.27$ & 0.179 \\
\hline Increase from baseline (\%) & $21 \pm 30$ & $14 \pm 12$ & $23 \pm 32$ & $18 \pm 29$ & 0.705 \\
\hline
\end{tabular}

${ }^{*}$ Cold pressor testing was performed on only a subgroup of patients $(n=79)$, of whom 5 had no features of metabolic syndrome, 41 had 1 or 2 features, and 33 had 3 or more features. Rest of table contains data for entire group of patients $(n=349)$, of whom 34 had no features of metabolic syndrome, 185 had 1 or 2 features, and 130 had 3 or more features.

Data are mean \pm SD. 


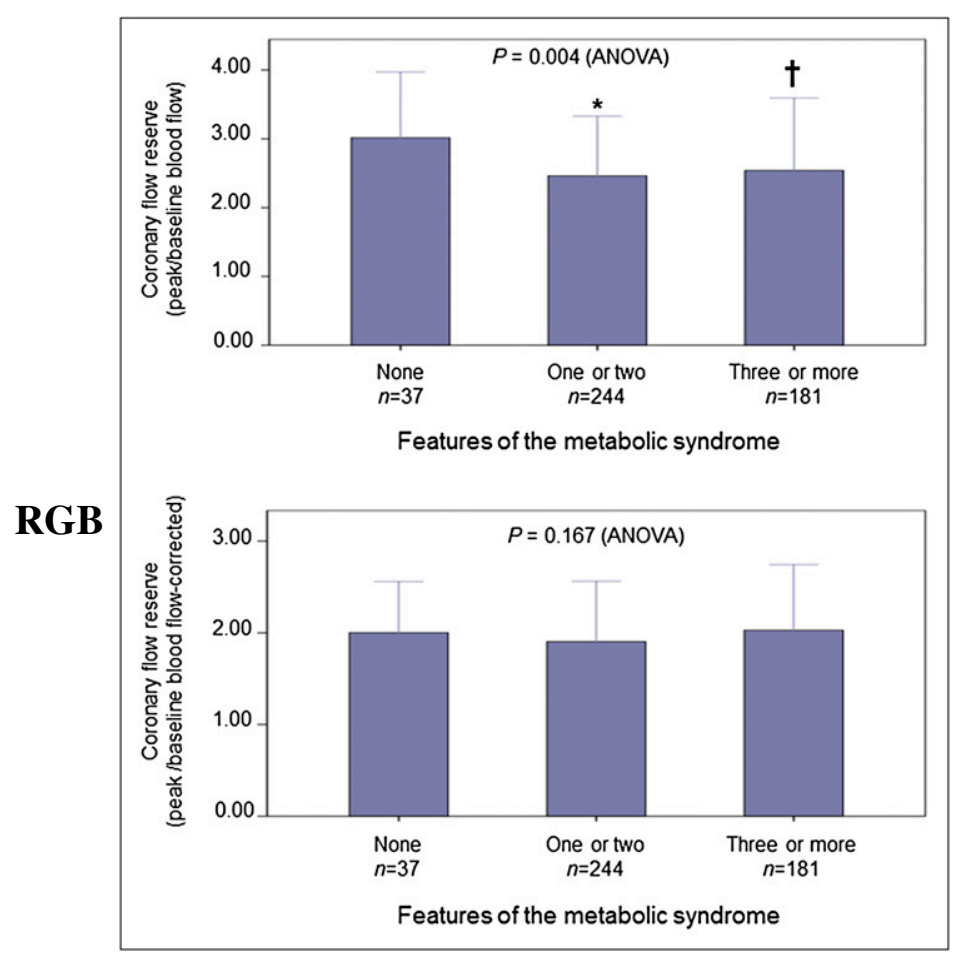

FIGURE 3. Relationship between mean coronary flow reserve (ratio between adenosine-stimulated and baseline coronary blood flow) (top) and corrected coronary flow reserve (bottom) and features of metabolic syndrome. ${ }^{*} P=0.003$ vs. none. ${ }^{\dagger} P=0.015$ vs. none.

blood flow during cold pressor testing was approximately $60 \%$ lower than that reported in nonobese healthy subjects $(8,17)$. Therefore, our findings are consistent with the presence of impaired vasodilator responses to both adenosine and cold pressor testing in at-risk individuals, such as those included in the study, and provide further evidence for the early presence of impaired endothelium-independent and endothelium-dependent coronary vasodilator function in patients with coronary risk factors. Importantly, our study

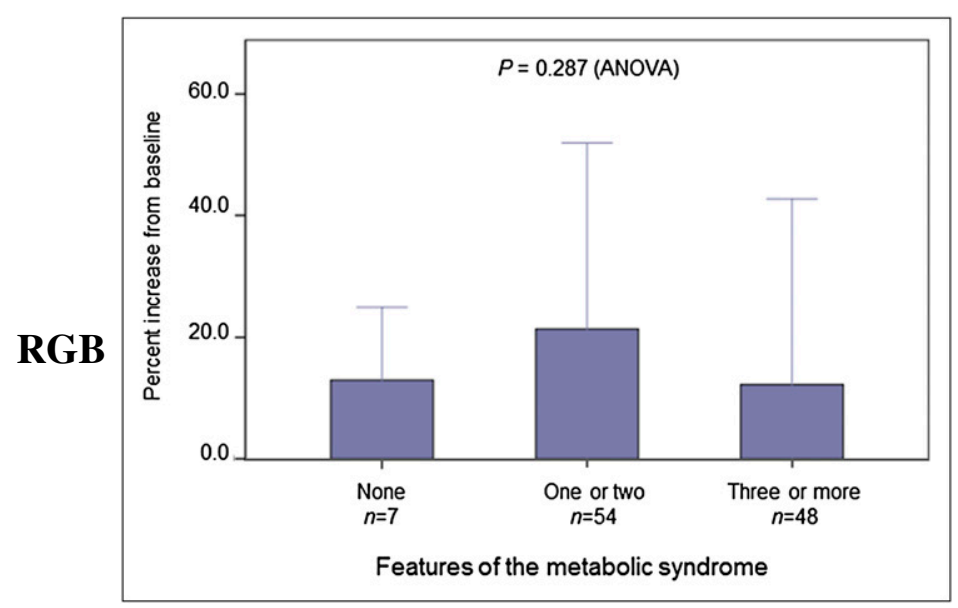

FIGURE 4. Subgroup analysis demonstrating relationship between coronary blood flow response to cold pressor testing and features of metabolic syndrome. suggests that these abnormalities in coronary vasodilator function are not worsened by the combined presence of high-risk features that define the metabolic syndrome.

The vasodilator response to adenosine reflects the integrated effects of both vascular smooth muscle and endothelial cell function (27), whereas the corresponding increase in blood flow in response to cold reflects primarily endothelium-mediated vasodilation (28). The finding that peak adenosine- and cold-stimulated MBF was similar in patients with and without the metabolic syndrome suggests a rather weak contribution of insulin resistance per se to coronary microvascular dysfunction, beyond that caused by alreadyestablished cardiovascular risk factors (i.e., dyslipidemia, smoking, and $\mathrm{CAD}$ ). These findings are new and potentially important and consistent with a recent analysis of an 8-y follow-up of 3,323 Framingham offspring (29). In this analysis, Framingham investigators examined whether the cardiovascular risk of metabolic syndrome is greater than the sum of its component risk factors. The results of this analysis suggest that most of the risk associated with the metabolic syndrome is captured by age, blood pressure, total cholesterol, diabetes, and HDL-C. Beyond these, abdominal obesity, triglycerides, and fasting glucose levels (in the absence of diabetes) added little to the power of prediction.

In asymptomatic subjects without clinical CAD, coronary flow reserve shows a modest inverse relationship with estimated 10-y Framingham coronary heart disease risk (30). Although the metabolic syndrome is related to an increased risk of CAD events, individuals with metabolic syndrome encompass a wide range of risk levels (31). The findings of this study suggest that the addition of higher risk patients with metabolic syndrome does not contribute significantly to the identification of patients with abnormal microvascular function beyond the information provided by individual risk factors in lower risk individuals. A quarter of the patients in this study had documented CAD. Although the metabolic syndrome has been used as an educational target to decrease the risk of diabetes and CAD in the general population, its presence has clinical importance even after CAD develops. Indeed, in the EUROPA trial including more than 8,000 patients with established CAD, the metabolic syndrome was associated with greater than a 2 -fold increase in cardiovascular death, and a 50\% increase in the frequency of myocardial infarction, even after adjustment for conventional risk factors (10). The effect of the metabolic syndrome on cardiovascular events was independent of its association with diabetes, and the risks associated with diabetes and the metabolic syndrome were incremental to each other. Similar findings have been reported in the WIZARD study (11). Our findings suggest that the increased risk associated with the metabolic syndrome in high-risk individuals may be related to the effect of insulin resistance on atherosclerosis burden (32) rather than coronary microvascular function (33).

In multivariable analysis, factors that were independently associated with an impaired coronary vasodilator reserve 
TABLE 4

Change in MBF and Coronary Vascular Resistance over Time in Patients with Baseline and Follow-up Scanning

\begin{tabular}{|c|c|c|c|c|c|}
\hline \multirow[b]{2}{*}{ Variable } & \multirow[b]{2}{*}{ All patients } & \multicolumn{3}{|c|}{ Patients with features of metabolic syndrome } & \multirow[b]{2}{*}{$P$} \\
\hline & & No features & 1 or 2 features & 3 or more features & \\
\hline \multicolumn{6}{|c|}{ Rest MBF (mL/min/g) } \\
\hline Baseline & $0.83 \pm 0.24$ & $0.70 \pm 0.16$ & $0.82 \pm 0.26$ & $0.87 \pm 0.24$ & 0.07 \\
\hline Follow-up & $0.79 \pm 0.26$ & $0.74 \pm 0.20$ & $0.79 \pm 0.2$ & $0.81 \pm 0.27$ & 0.23 \\
\hline Change at $1 \mathrm{y}$ & $-0.04 \pm 0.07$ & $0.03 \pm 0.26$ & $-0.02 \pm 0.25$ & $-0.06 \pm 0.28$ & 0.84 \\
\hline \multicolumn{6}{|c|}{$\begin{array}{l}\text { Hyperemic MBF } \\
\qquad(\mathrm{mL} / \mathrm{min} / \mathrm{g} \text { of tissue })\end{array}$} \\
\hline Baseline & $1.69 \pm 0.57$ & $1.80 \pm 0.58$ & $1.66 \pm 0.51$ & $1.72 \pm 0.65$ & 0.19 \\
\hline Follow-up & $1.78 \pm 0.68$ & $1.71 \pm 0.57$ & $1.78 \pm 0.69$ & $1.79 \pm 0.69$ & 0.95 \\
\hline Change at $1 \mathrm{y}$ & $0.08 \pm 0.68$ & $-0.09 \pm 0.82$ & $0.12 \pm 0.66$ & $0.07 \pm 0.69$ & 0.82 \\
\hline \multicolumn{6}{|c|}{$\begin{array}{l}\text { Coronary vasodilator } \\
\text { reserve }\end{array}$} \\
\hline Baseline & $2.13 \pm 0.75$ & $2.60 \pm 0.84$ & $2.11 \pm 0.66$ & $2.09 \pm 0.84$ & 0.01 \\
\hline Follow-up & $2.37 \pm 0.98$ & $2.34 \pm 0.70$ & $2.35 \pm 1.00$ & $2.40 \pm 1.01$ & 0.91 \\
\hline Change at $1 \mathrm{y}$ & $0.24 \pm 1.00$ & $-0.26 \pm 1.06$ & $0.24 \pm 1.00$ & $0.32 \pm 0.98$ & 0.96 \\
\hline \multicolumn{6}{|c|}{$\begin{array}{l}\text { Rest coronary } \\
\text { vascular resistance } \\
(\mathrm{mL} / \mathrm{min} / \mathrm{g} / \mathrm{mm} \mathrm{Hg})\end{array}$} \\
\hline Baseline & $120.1 \pm 33.2$ & $121.5 \pm 24.7$ & $121.3 \pm 34.3$ & $118.3 \pm 33.3$ & 0.07 \\
\hline Follow-up & $125.9 \pm 40.2$ & $124.8 \pm 37.5$ & $123.4 \pm 38.6$ & $129.4 \pm 42.8$ & 0.33 \\
\hline Change at $1 \mathrm{y}$ & $5.75 \pm 40.9$ & $3.38 \pm 47.7$ & $2.12 \pm 39.4$ & $11.1 \pm 41.6$ & 0.46 \\
\hline \multicolumn{6}{|c|}{$\begin{array}{l}\text { Hyperemic coronary } \\
\text { vascular resistance } \\
(\mathrm{mL} / \mathrm{min} / \mathrm{g} / \mathrm{mm} \mathrm{Hg})\end{array}$} \\
\hline Baseline & $59.3 \pm 24.3$ & $51.2 \pm 16.8$ & $58.7 \pm 20.7$ & $61.5 \pm 29.4$ & 0.34 \\
\hline Follow-up & $58.4 \pm 25.6$ & $56.4 \pm 20.6$ & $57.5 \pm 26.1$ & $59.9 \pm 26.0$ & 0.99 \\
\hline Change at $1 \mathrm{y}$ & $-0.93 \pm 27.1$ & $5.29 \pm 28.8$ & $-1.26 \pm 24.5$ & $-1.56 \pm 30.2$ & 0.89 \\
\hline
\end{tabular}

$n=234$ for all patients, 16 for patients with no features of metabolic syndrome, 125 for patients with 1 or 2 features, and 93 for patients with 3 or more features. Data are mean \pm SD.

included a history of hypertension, a history of prior CAD, age, and active smoking. No other features of the metabolic syndrome contributed significantly to the prediction of the impaired coronary vasodilator reserve in this high-risk population. The results of multivariable modeling were similar in the subgroup of patients without overt CAD, suggesting a dynamic contribution of different risk factors at various stages in the development of atherosclerosis. It is recognized that dyslipidemia $(5,6)$, diabetes $(7)$, and hypertension (34) contribute to impaired coronary flow reserve when each is present in isolation. However, as these factors coalesce and the metabolic syndrome develops, hypertension, age, smoking, and, ultimately, obstructive CAD predominate in determining the health of the coronary vasculature. Indeed, by the time these patients become high-risk, as in this study, the constellation of risk factors associated with the metabolic syndrome per se appears to have a less substantive effect in determining vascular health.

A novel feature of our study design is that it allowed us to analyze the association of the metabolic syndrome with changes in perfusion, vascular resistance, and flow reserve after $1 \mathrm{y}$ of follow-up. To our knowledge, ours is the first study to examine the effects of the metabolic syndrome on longitudinal changes in indices of myocardial perfusion. Interestingly, we did not find any significant associations between the metabolic syndrome and the change in these indices over time. These data should be interpreted within the context of the relatively small sample size, relatively short duration of follow-up, and requirement for a baseline reduced flow reserve in the cohort undergoing repeated imaging. Nevertheless, our finding that the presence of the metabolic syndrome is not associated with accelerated losses of $\mathrm{MBF}$ and flow reserve or greater increases in vascular resistance at $1 \mathrm{y}$ lends supports to the concept that insulin resistance may not substantively affect endothelial function in individuals with preexisting cardiovascular disease, advanced age, hypertension, or smoking.

Our results contrast with a previous study reporting an association between obesity and insulin resistance and endothelial dysfunction (35). Steinberg et al. reported a blunted increase in leg blood flow in response to methacholine in a small group of young obese and insulin-resistant subjects, compared with a group of lean controls (35). In the study by Steinberg et al., however, there were important differences in lipids (HDL-C, LDL-C, and triglycerides) and blood pressure between the obese and insulin-resistant subjects and the controls. Thus, it is difficult to ascertain the relative contribution of the differences in lipids and blood pressure between the patients and controls and insulin resistance per se to the observed abnormalities in endothe- 
lium-dependent blood flow increase in response to methacholine.

Several factors should be considered when interpreting the results of this study. Although the data were collected on a prospective cohort, the analysis is retrospective. The study substituted BMI over waist circumference in calculating the number of components of the metabolic syndrome. Although waist circumference is a preferable measure of abdominal obesity, as explained it is closely related to BMI $(15,16)$ and predictive of cardiovascular events $(10,16)$.

\section{CONCLUSION}

This study demonstrates that in high-risk patients, the cluster of metabolic and hemodynamic abnormalities present with the metabolic syndrome are associated with impaired coronary vasodilator reserve, even in the absence of obstructive CAD. This abnormality appears to be related to an augmentation in resting $\mathrm{MBF}$, likely reflecting the increased blood pressure in patients with metabolic syndrome. Our finding that peak adenosine- and cold-stimulated blood flows are impaired in patients with established cardiovascular risk factors, even in the absence of the metabolic syndrome, suggests that by the time patients develop high-risk characteristics, the contribution of the metabolic syndrome to coronary microvascular health is diminished.

\section{DISCLOSURE STATEMENT}

The costs of publication of this article were defrayed in part by the payment of page charges. Therefore, and solely to indicate this fact, this article is hereby marked "advertisement" in accordance with 18 USC section 1734.

\section{ACKNOWLEDGMENTS}

We thank the women and men who participated in this study. We also acknowledge the valuable contributions of other RAMPART investigators and their clinical and technical staff. This study was supported in part by an American Heart Association scientist development grant. No other potential conflict of interest relevant to this article was reported.

\section{REFERENCES}

1. Reaven GM. Banting lecture 1988. Role of insulin resistance in human disease. Diabetes. 1988;37:1595-1607.

2. Ford E, Giles W, Dietz W. Prevalence of the metabolic syndrome among U.S. adults: findings from the third National Health and Nutrition Examination Survey. JAMA. 2002;287:356-359.

3. Watarai T, Yamasaki Y, Ikeda M, et al. Insulin resistance contributes to carotid arterial wall thickness in patients with non-insulin-dependent-diabetes mellitus. Endocr J. 1999;46:629-638.

4. DeFronzo RA. Insulin resistance: a multifaceted syndrome responsible for NIDDM, obesity, hypertension, dyslipidaemia and atherosclerosis. Neth J Med. 1997;50:191-197.

5. Dayanikli F, Grambow D, Muzik O, Mosca L, Rubenfire M, Schwaiger M. Early detection of abnormal coronary flow reserve in asymptomatic men at high risk for coronary artery disease using positron emission tomography. Circulation. 1994;90:808-817.
6. Pitkänen OP, Nuutila P, Raitakari OT, et al. Coronary flow reserve in young men with familial combined hyperlipidemia. Circulation. 1999;99:1678-1684.

7. Di Carli MF, Janisse J, Grunberger G, Ager J. Role of chronic hyperglycemia in the pathogenesis of coronary microvascular dysfunction in diabetes. J Am Coll Cardiol. 2003;41:1387-1393.

8. Schindler TH, Cardenas J, Prior JO, et al. Relationship between increasing body weight, insulin resistance, inflammation, adipocytokine leptin, and coronary circulatory function. J Am Coll Cardiol. 2006;47:1188-1195.

9. Hsueh WA, Law R. The central role of fat and effect of peroxisome proliferatoractivated receptor-gamma on progression of insulin resistance and cardiovascular disease. Am J Cardiol. 2003;92(4A):3J-9J.

10. Daly CA, Hildebrandt P, Bertrand M, et al. Adverse prognosis associated with the metabolic syndrome in established coronary artery disease: data from the EUROPA trial. Heart. 2007;93:1406-1411.

11. Aguilar D, Fisher MR, O'Connor CM, et al. Metabolic syndrome, C-reactive protein, and prognosis in patients with established coronary artery disease. $\mathrm{Am}$ Heart J. 2006;152:298-304.

12. Rewers M, Zaccaro D, D'Agostino R, et al. Insulin sensitivity, insulinemia, and coronary artery disease: the Insulin Resistance Atherosclerosis Study. Diabetes Care. 2004;27:781-787.

13. Forgione MA, Leopold JA, Loscalzo J. Roles of endothelial dysfunction in coronary artery disease. Curr Opin Cardiol. 2000;15:409-415.

14. Expert Panel on Detection E, and Treatment of High Blood Cholesterol in Adults. Executive Summary of the Third Report of the National Cholesterol Education Program (NCEP) Expert Panel on Detection, Evaluation, and Treatment of High Blood Cholestrol in Adults (Adult Treatment Panel III). JAMA. 2001;285:2486-2497.

15. Wong ND, Sciammarella MG, Polk D, et al. The metabolic syndrome, diabetes, and subclinical atherosclerosis assessed by coronary calcium. J Am Coll Cardiol. 2003;41:1547-1553.

16. Sattar N, Gaw A, Scherbakova O, et al. Metabolic syndrome with and without C-reactive protein as a predictor of coronary heart disease and diabetes in the West of Scotland Coronary Prevention Study. Circulation. 2003;108: 414-419.

17. Di Carli MF, Bianco-Batlles D, Landa ME, et al. Effects of autonomic neuropathy on coronary blood flow in patients with diabetes mellitus. Circulation. 1999;100:813-819.

18. Myers GL, Cooper GR, Winn CL, Smith SJ. The Centers for Disease Control-National Heart, Lung, and Blood Institute Lipid Standardization Program. An approach to accurate and precise lipid measurements. Clin Lab Med. 1989;9:105-135.

19. Steiner PM, Freidel J, Breminer WF, Stein E. Standardization of micromethods for plasma cholesterol, triglyceride and HDL-cholesterol with the Lipid Clinic's Methodology. J Clin Chem Clin Biochem. 1981;19:850.

20. Steele BW, Koehler DR, Azar MM, Blaszkowski TP, Kuba K, Dempsey ME. Enzymatic determinations of cholesterol in high-density-lipoprotein fractions prepared by the precipitation technique. Clin Chem. 1976;22:98-101.

21. Friedewald WT, Levy R, Fredrickson DS. Estimation of the concentration of low-density lipoprotein cholesterol in plasma without use of the preparative ultracentrifuge. Clin Chem. 1972;18:499-502.

22. Rifai N, Tracy RP, Ridker PM. Clinical efficacy of an automated high-sensitivity C-reactive protein assay. Clin Chem. 1999;45:2136-2141.

23. Reaven GM. Role of insulin resistance in the pathophysiology of non-insulin dependent diabetes mellitus. Diabetes Metab Rev. 1993;9(suppl 1):5S-12S.

24. Reaven GM. Insulin resistance, compensatory hyperinsulinemia, and coronary heart disease: syndrome X revisited. In: Jefferson LS, Cherrington AD, eds. Handbook of Physiology, Section 7, The Endocrine System, Vol. II, The Endocrine Pancreas and Regulation of Metabolism. New York, NY: Oxford University Press; 2001:1169-1197.

25. Haffner SM. Insulin resistance, inflammation, and the prediabetic state. Am J Cardiol. 2003;92(4A):18J-26J.

26. Di Carli M, Czernin J, Hoh CK, et al. Relation among stenosis severity, myocardial blood flow, and flow reserve in patients with coronary artery disease. Circulation. 1995;91:1944-1951.

27. Smits P, Williams SB, Lipson DE, Banitt P, Rongen GA, Creager MA. Endothelial release of nitric oxide contributes to the vasodilator effect of adenosine in humans. Circulation. 1995;92:2135-2141.

28. Nabel EG, Ganz P, Gordon JB, Alexander RW, Selwyn AP. Dilation of normal and constriction of atherosclerotic coronary arteries caused by the cold pressor test. Circulation. 1988;77:43-52.

29. Grundy SM. Obesity, metabolic syndrome, and cardiovascular disease. J Clin Endocrinol Metab. 2004;89:2595-2600.

30. Dorbala S, Hassan A, Heinonen T, Schelbert HR, Di Carli MF. Coronary vasodilator reserve and Framingham risk scores in subjects at risk for coronary artery disease. J Nucl Cardiol. 2006;13:761-767. 
31. Hoang KC, Ghandehari H, Lopez VA, Barboza MG, Wong ND. Global coronary heart disease risk assessment of individuals with the metabolic syndrome in the U.S. Diabetes Care. 2008;31:1405-1409.

32. Nissen SE, Nicholls SJ, Wolski K, et al. Comparison of pioglitazone vs glimepiride on progression of coronary atherosclerosis in patients with type 2 diabetes: the PERISCOPE randomized controlled trial. JAMA. 2008;299:1561-1573.

33. McMahon GT, Plutzky J, Daher E, Bhattacharyya T, Grunberger G, DiCarli MF. Effect of a peroxisome proliferator-activated receptor-gamma agonist on myocardial blood flow in type 2 diabetes. Diabetes Care. 2005;28:1145-1150.

34. Hamasaki S, Al Suwaidi J, Higano ST, Miyauchi K, Holmes DR Jr, Lerman A. Attenuated coronary flow reserve and vascular remodeling in patients with hypertension and left ventricular hypertrophy. J Am Coll Cardiol. 2000;35:1654-1660.

35. Steinberg HO, Chaker H, Leaming R, Johnson A, Brechtel G, Baron AD. Obesity/insulin resistance is associated with endothelial dysfunction: implications for the syndrome of insulin resistance. J Clin Invest. 1996;97:2601-2610. 